Claremont Colleges

Scholarship@ Claremont

CGU Theses \& Dissertations

CGU Student Scholarship

1998

\title{
Multiple Intelligence Theory and its Application in Modern Vocal Pedagogy
}

Robb Dennis

Claremont Graduate University

\section{Recommended Citation}

Dennis, Robb. (1998). Multiple Intelligence Theory and its Application in Modern Vocal Pedagogy. CGU Theses \& Dissertations, 99. http://scholarship.claremont.edu/cgu_etd/99. doi: 10.5642/cguetd/99

This Open Access Dissertation is brought to you for free and open access by the CGU Student Scholarship at Scholarship @ Claremont. It has been accepted for inclusion in CGU Theses \& Dissertations by an authorized administrator of Scholarship @ Claremont. For more information, please contact scholarship@cuc.claremont.edu. 


\title{
MULTIPLE INTELLIGENCE THEORY AND ITS APPLICATION IN MODERN VOCAL PEDAGOGY
}

\author{
BY
}

\section{ROBB DENNIS}

\begin{abstract}
A Final Project submitted to the Faculty of Claremont Graduate University in partial fulfillment of the requirements for the degree of Doctor of Musical Arts in the Graduate Faculty of Music.
\end{abstract}

Claremont, California

1998

Approved by:

Dr. Frank Traficante 
(C) Copyright by Robb Dennis 1998

All Rights Reserved 
We, the undersigned, certify that we have read this project paper and approve it as adequate in scope and quality for the degree of Doctor of Musical Arts.

\section{Project Paper Committee:}

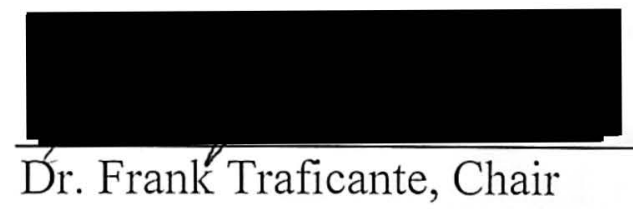

Di. Jane O’Donnell

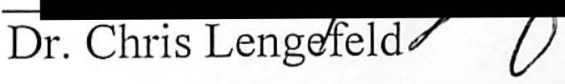




\section{ACKNOWLEDGEMENTS}

Thanks are due to the following individuals for their support of this project: to Dr. Jane O'Donnell for her enthusiastic support and encouragement from the very beginning and for being a patient mentor; to Dr. Frank Traficante and Dr. Chris Lengefeld for many hours of editing during their summer vacations; to Leilani Balan for her knowledge of Turabian and speedy transcription; and to Bonnie and Gabrielle for patience while this project consumed time and resources of the Dennis household.

The writings of Howard Gardner, Thomas Armstrong, Van Christy, and Jan Schmidt have formed the cornerstones of this paper and are greatly appreciated. 


\section{Abstract of the Final Project Paper \\ MULTIPLE INTELLIGENCE THEORY AND ITS APPLICATION IN MODERN VOCAL PEDAGOGY}

\section{BY \\ ROBB DENNIS \\ Claremont Graduate University: 1998}

In 1983, Howard Gardner shook the foundations of intelligence testing and the field of education by suggesting that there are seven distinct intelligences. These intelligences had testable and distinct attributes that were supported by his research at the Boston Veterans Administration. This research cited the existence of savants and prodigies, isolation by brain damage, and psychometric findings as support for Multiple Intelligence Theory. Widely accepted by the education community at large, the application of MI principles has been further elaborated in the writings of Thomas Armstrong and David Lazear. Can the principles of Multiple Intelligence Theory be applied in the area of modern vocal pedagogy? After surveys of the foundations of vocal pedagogy and the principles of MI theory, the author suggests they can. What follows is an analysis of two current vocal pedagogy texts, Van Christy's Foundations in Singing and Jan Schmidt's Basics of Singing to determine the variety and use of MI principles in each. After the analysis, the author suggests applications of MI principles, using aspects of their song learning chapters as a template that can be adapted to any vocal pedagogy text. 


\section{CONTENTS}

ACKNOWLEDGEMENTS ...iv

ABSTRACT OF THE FINAL PROJECT PAPER.................................................................................

Chapter

Page

1 THE HISTORICAL FOUNDATIONS OF MODERN VOCAL PEDAGOGY $\ldots 1$

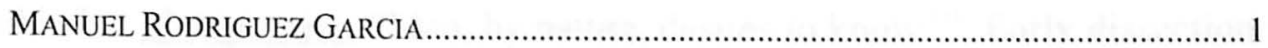

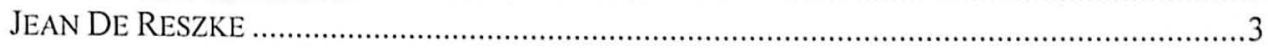

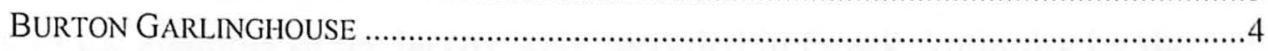

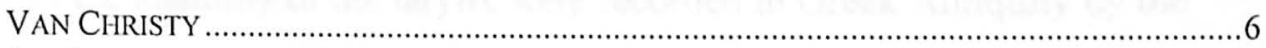

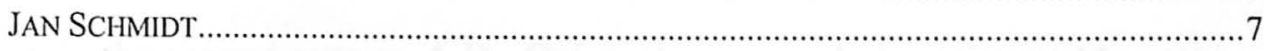

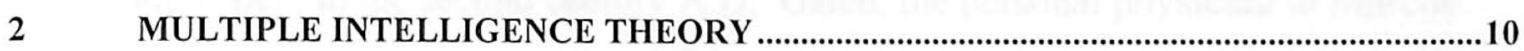

3 MULTIPLE INTELLIGENCE THEORY AND MODERN VOCAL PEDAGOGY ..............17

DRAWBACKS OF CURRENT INSTRUCTION PRACTICES................................................... 18

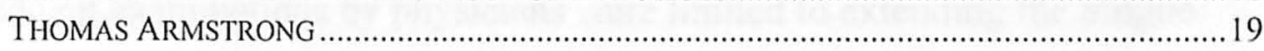

4 ANALYSIS OF VAN CHRISTY AND JAN SCHMIDT TEXTS ….....................................21

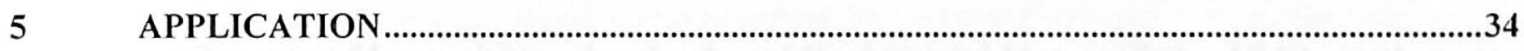

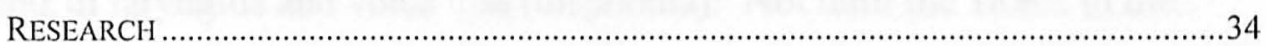

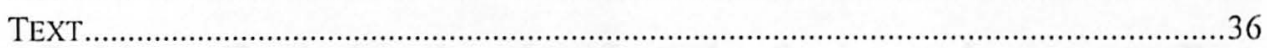

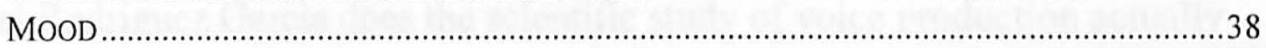

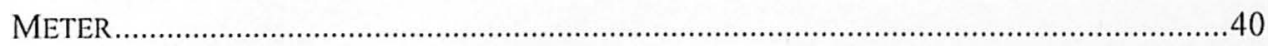

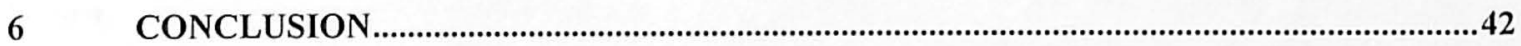

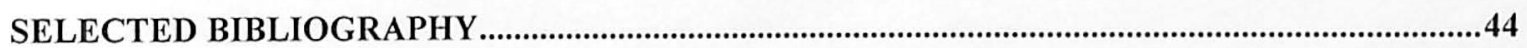




\section{CHAPTER 1}

\section{THE HISTORICAL FOUNDATIONS OF MODERN VOCAL PEDAGOGY}

The human voice has a long history of inquiry, perhaps because of Aristotle's core truth mentioned in his Metaphysics, "Man, by nature, desires to know." Early dissection and exploration of the anatomy of the larynx were recorded in Greek Antiquity by the physician, Galen, in the second century A.D. Galen, the personal physician to Marcus Aurelius, was the first to hypothesize that the vocal cords produced singing and speaking sounds. Subsequent examinations by physicians were limited to extending the tongue and palpitating the throat tissues at the base of the tongue to discover the reasons for common ailments of laryngitis and voice loss (disphonia). ${ }^{2}$ Not until the 1840s in the work of Manuel Rodriguez Garcia does the scientific study of voice production actually begin.

\section{Manuel Rodriguez Garcia}

The son of famous Royal Opera tenor Manuel Vicente Garcia, Manuel Rodriguez distinguished himself as a stage singer but in 1829 adopted his father's recently established interest in vocal coaching. Achieving some success with his students, he further investigated the functions of the vocal organs using the laryngoscope, a type of dental mirror by which he could observe vocal cord function. By grasping the tongue

\footnotetext{
${ }^{1}$ William Benton, The Works of Aristotle, vol. 2 (Chicago: Encyclopedia Britannica, 1952), 682.

${ }^{2}$ David Lawrence, The Voice Once Over Lightly (Philadelphia: Voice Foundation, 1988), transcript of video recording, 1.
} 
firmly, placing the mirror behind the back of the tongue, and shining a bright light in the oral cavity, Garcia observed vocal cord movements that before this time had only been hypothesized. He then recorded his findings and views on voice production in $\underline{\mathrm{A}}$ Complete Treatise on the Art of Singing I, II $(1841,1872)$. He was the first to write in detail on voice classification, describing the individual voice types according to their range, weight, and timbre. The first scientific voice experiments in registration were conducted by him using his students as subjects:

A singer having his chest as filled with air as it could be, produced, with the full voice, a determined note, taken in the part common to the two registers, and he sustained this vocal sound until the air contained in his lungs was exhausted. The pendulum of a metronome served by its oscillations to indicate the time during which that vocal sound lasted; then, having refilled his lungs with air, the singer produced the same note with the falsetto voice, and he sustained it as long as that was possible for him. Now we saw, in these two experiments repeated several times, that the pendulum offered twenty-four to twenty-six oscillations during the length of the full voice sound, while it offered only sixteen to eighteen oscillations during the length of the same sound in the falsetto voice.

This experiment proves that, in a given time, and for the production of the same diatonic tone, the vocal instrument spends more air while producing the falsetto voice than while producing the full or chest voice. ${ }^{3}$

For the discovery of this method of investigation, Garcia received an honorary Ph.D. from Königsburg University. His students benefited greatly from his interest in vocal science. A list of Manuel's star pupils would make up much of a "Who's Who in Singing" for the final seven decades of the nineteenth century, as well as the beginning of the twentieth century. He moved from Paris to London in 1848 and taught at the Royal Academy of Music until his retirement in 1895 at the age of ninety. After that, he taught

${ }^{3}$ Manuel Garcia, A Complete Treatise on the Art of Singing: Part One, trans. Donald V. Paschke (New York: Da Capo Press, 1984), 28, 29. 
at his home until very shortly before his death on July 1, 1906, at the age of 101 years. His most distinguished pupil was undoubtedly Jenny Lind. Among the others were Mathilde Marchesi, who became a very famous teacher in her own right, Julius Stockhausen, one of Germany's greatest singers and teachers, and Sir Charles Santley in England. Richard Wagner sent his niece, Johanna, to Garcia in 1845, and many years later invited him to train the singers for the first Bayreuth Festival, an honor that Garcia declined because of his heavy schedule. ${ }^{4}$ Incidentally, his laryngoscope is still used by otolaryngologists today as a preliminary tool for diagnosis in the first visit, being cheaper and less invasive than the modern fiber optic laryngoscopy. Certainly, his impact on vocal science was immense.

\section{Jean De Reszke}

The next significant development in vocal pedagogy was in the area of sensations and resonance by the celebrated tenor and vocal coach, Jean De Reszke. Born in Warsaw as Jan Mieczislaw in 1850, De Reszke emigrated to France as a young man to study as a baritone with Sbriglia. ${ }^{5}$ With Sbriglia, De Reszke began to experiment with the concept of resonance as a sensation that could be felt in the head, particularly while singing palatals (nasal vowel sounds) of the French language. He maintained that resonance could be controlled by the movement of the soft palette and that the projection of the voice could be increased by focusing the sound into the nasal cavity by consciously dropping the soft palette. This process was accomplished in students using aural imagery

\footnotetext{
${ }^{4}$ Ibid., 7.

${ }^{5}$ New Grove's Dictionary of Music and Musicians (1980), s.v. "De Reszke, Jean."
} 
(mind pictures) in which the student visualized deliberately placing the tone in the masque of the face (adjusting the soft palette and throat in order to feel vibrations in the forehead, bridge of the nose, and back of the head). ${ }^{6}$

Along with his "masque resonance," De Reszke had interesting views on head positioning. He said, "Sing in the gallery," which meant he wanted the head slightly back of natural resting position, the back of the head high, and the chin slightly lowered so that you "feel like you are butting your way through." Science has shown in the studies of Luchsinger and Arnold that the elevator and depressor muscles of the larynx in opposition assist in shortening the vocal cords for higher pitches. The pitch of the vocal tract is higher with the head in the "Gallery" position, possibly increasing the ease of high notes. ${ }^{8}$ De Reszke emphasized lip movement and cheek movement in the form of "la grimace de la chanteuse" (the singer's grimace). The cheeks should rise as the pitch rises to help male and female voices in their upper register.

\section{Burton Garlinghouse}

Though many variations on the themes of Garcia and De Reszke could be mentioned, these methods form a foundation on which methods of vocal pedagogy branch out in the twentieth century. Burton Garlinghouse, considered the "dean of vocal pedagogy" by some, defines three main approaches to vocal pedagogy: bel canto, psychological/imagery, and mechanistic (scientific).

${ }^{6}$ Berton Coffin, Historical Vocal Pedagogy Classics (London: Scarecrow Press, 1989), 108.

${ }^{7}$ Douglas Johnstone, "The Teaching of De Reszke," Music and Letters 1 (July 1925) : 9.

${ }^{8}$ Robert Luchsinger and George Arnold, Voice-Speech-Language (Belmont, CA: Wadsworth Publishing, 1965), 67. 
The bel canto (It. "beautiful singing") school flourished in the eighteenth century, primarily in Italy, and was carried on into the twentieth century by such artists as Caruso and Gigli. Its most widely recognized attribute is its emphasis on legato singing.

Relying heavily on metaphor and psychological suggestions, the psychological/imagery school is audible in modern pedagogy in such remarks as "darken the vowel," "feel the resonance in the bridge of the nose," and "drink in the tone." It treats the singer as an emotional, feeling provoked, and thought driven entity, with little concern for scientific explanation. Concepts of throat shape and breath support are illustrated in terms using the body's reflex actions such as yawning and focusing the air toward a fixed point in the room.

Alongside a renewed interest in empirical science, the mechanistic approach arose in the mid-1800s as a response to anatomical and acoustical curiosity. Its contribution to our understanding of vocal resonance is considerable. In contrast to the more "subjective" psychological/imagery approach, the mechanistic school might be regarded as the "objective" approach."

The similarities in terminology between the De Reszke and Garlinghouse's psychological/imagery approach are striking. Both use the tone placement metaphors having to do with body parts. Other significant phrases used in the psychological/imagery method include: "place the tone forward toward the teeth," "roll the tone up and back in the head for high tones," "feel the tone between your eyes," and "smile the tone on the inside." From this evidence, it would be fair to say, in summary, that Manuel Garcia is the father of the mechanist school and Jean De Reszke is the father of the psychological/imagery school.

Contemporary vocal pedagogues, Van Christy and Jan Schmidt, have decidedly different approaches to vocal instruction. To confirm their pedagogical foundation(s), I have analyzed their work according to the previously mentioned parameters, using Chapter Four in the Christy text, Foundations in Singing, and Chapter Five in the

${ }^{9}$ Richard Harpster, Technique in Singing (New York: Schirmer Books, 1984), 1-2. 
Schmidt text, Basics of Singing. Though both of these chapters focus on resonance and registration, they are explained in entirely different ways.

\section{Van Christy}

The title of Van Christy's chapter gives away his pedagogical foundation:

"Changing Resonances in Your Voice." To understand what he means, one must read on:

Centuries ago singers noticed these sensations. Not knowing about the larynx, they thought that certain tones really originated in the chest and others in the head. This is not true - chest vibration is simply a response to a tone, a sympathetic vibration. However, many singers still speak of chest voice and head voice because of the familiar sensations that accompany our low and high registers. ${ }^{10}$

His use of the terms common to the paradigm of Jean De Reszke in the area of sensation are in evidence throughout this example. If Christy were a mechanist, physiological terms, such as crico-arytenoid and thyro-arytenoid, would be used to explain the vocal cord changes when using the high and low voice." Instead, the discussion focuses on sensation, vibration, and their occurrence in various areas of the body.

There are particularly strong indications of imagery theory in the practical exercises at the end of the chapter:

${ }^{10}$ Van Christy, Foundations in Singing, $5^{\text {th }}$ ed. (Dubuque, IA: Wm. C. Brown, 1990), 27.

${ }^{11}$ It is interesting that he couples the areas of resonance and registration together in the same chapter with regard to sensation. Scientifically speaking, resonance is what happens to the sound wave after it leaves the vocal folds, and registration is how laryngeal muscles work together to produce the full range of pitches in the human voice. They could only be related in terms of sensations felt when each voice is produced. The fallacy is in what is meant by resonance. In vocal pedagogy and vocal science, resonance is spoken of as a source of vocal power. Formants (sound wave patterns) form a standing wave (a sound wave that reinforces itself) through the interaction of an expanded throat and flexed mucosal tissue lining the pharyngeal space that can magnify the human voice up to 110 decibels. 
4.1 Mental Messages. Imagine the muscles of the cheekbones under the eyes completely relaxed, the lips loose, the tongue lying forward in the mouth and the jaw hanging freely.

4.8 Little Arches. Even before you sing the first note, have the first two notes of each phrase in mind. If you do this, the upward jump will be in tune and the tones will connect smoothly (automatically just right).

4.12 5-note Ee-ah's. Start on any easy note around the mid-point of your range. Sense the brightness of the first vowel and let the brightness carry to the second vowel.

4.13 Focusers. Try these combinations of syllables, which have been used by many singers to "center their vocal energy" (emphases mine). ${ }^{12}$

Many of these mind pictures are effective for quick results with beginning singers, but those individuals with limited proprioception (ability to feel sensations in the body) might find these explanations confusing. Though these are just brief examples, his use of imagery remains consistent throughout, particularly in the practical application of his ideas in each chapter.

\section{Jan Schmidt}

In Basics of Singing, Jan Schmidt takes a more general approach to developing resonance. She begins the explanation of resonance principles with a survey of sound waves and how they travel:

As the wave fronts are emitted [from the vocal folds], billions of molecules of air are pushed outward in all directions from the source. The moving molecules do not experience a permanent displacement; after the wave passes by, they return to their original position. The moving outward of the molecules is termed compression, and the return of the molecules to their original position is called rarefaction. ${ }^{13}$

\footnotetext{
${ }^{12}$ Christy, 32, 33.

${ }^{13}$ Jan Schmidt, Basics of Singing, $4^{\text {th }}$ ed. (New York: Simon and Schuster Macmillan, 1998), 31.
} 
This scientific explanation of the nature of sound and wave properties segues into an explanation of resonance that has many characteristics common to mechanist terminology:

Resonance is a response to a produced sound, during which that sound is prolonged and intensified. The three main resonators for the voice are, in order of importance, the throat, the mouth, and the nose. Research has shown that, although a singer might feel sympathetic vibrations in the chest, trachea, larynx, or sinuses, those areas have little or no value as resonators. When the surfaces of the resonators are stretched to form a yawn or open throat, they are hardened, thereby conducting sound more effectively. The resonators also filter out, or dampen some sounds, a process that is even more evident when their surfaces are flaccid [unstretched by yawn].

It should be noted that the nose is an occasional resonator, while the throat and mouth function constantly as resonators. Nasal resonance is primarily necessary for the production of nasal consonants, such as $\mathrm{m}, \mathrm{n}$, and $\mathrm{ng}$. It is also important to the singing of foreign languages, most notably French, because of their nasal vowels.

The shape of the resonators determines, to a large extent, the quality of tone produced ... (emphases mine). ${ }^{14}$

One difference in the writing style of imagery theorists and mechanists is their approach to explanation in vocal pedagogy. The mechanistic wording is clearly evidenced in this explanation by Schmidt. Imagery theorists usually begin with questions to the student/reader considering the sensations they feel. Christy's comments on resonance are cited below:

Have you noticed that some parts of the voice feel different from others? Are there some notes that you can sing in more than one way? Untrained singers often feel uncomfortable about inconsistencies found between their low and high ... Try this experiment: place your hands on your ribs and sing the lowest note you can imagine. What do you feel? You probably feel vibrations. Now keep your hands on your ribs and sing a high, light note. Do you still feel the vibrations? ${ }^{15}$

\footnotetext{
${ }^{14}$ Ibid., 32.

${ }^{15}$ Christy, 27.
} 
The interrogatory style of this example is in direct contrast to the exclamatory style shown in Schmidt. The imagery theorists tend to begin with questions about what the reader feels and conclude with exercises supporting those sensations (see the previous Christy examples). The mechanists, however, begin with detailed explanations and definitions of terms having to do with vocal production and end with exercises supporting their hypotheses. Exploring the historical foundations of vocal pedagogy and defining the pedagogy schools of Van Christy and Jan Schmidt as evidenced in their writings will help to define and contrast the effectiveness of their vocal pedagogy texts from the context of Multiple Intelligence Theory. 


\section{CHAPTER 2}

\section{MULTIPLE INTELLIGENCE THEORY}

In 1983, Howard Gardner, a Harvard psychologist, proposed that the IQ tests of

Alfred Binet ${ }^{16}$ defined intelligence too narrowly. He seriously questioned the validity of determining an individual's intelligence through isolated tasks that he had never done before and probably would never choose to do again. In his book Frames of Mind, Gardner proposed the existence of at least seven basic intelligences:

Linguistic Intelligence: The capacity to use words effectively, whether orally (e.g., as a storyteller, orator, or politician) or in writing (e.g., as a poet, playwright, editor, or journalist). This intelligence includes the ability to manipulate the syntax, structure or language, the phonology or sound of language, the semantics or meanings of language, and the pragmatic dimensions or practical uses of language. Some of these uses include rhetoric (using language to convince others to take a specific course of action), mnemonics (using language to remember information), explanation (using language to inform), and metalanguage (using language to talk about itself).

Logical-Mathematical Intelligence: The capacity to use numbers effectively (e.g., as a mathematician, tax accountant, or statistician) and to reason well (e.g., as a scientist, computer programmer, or logician). This intelligence includes sensitivity to logical patterns and relationships, statements and propositions (if-then, cause-effect), functions, and other related abstractions. The kinds of processes used in the service of logical-mathematical intelligence include: categorization, classification, inference, generalization, calculation, and hypothesis testing.

Spatial Intelligence: The ability to perceive the visual-spatial world accurately (e.g., as a hunter, scout, or guide) and to perform transformations upon those perceptions (e.g., as an interior decorator, architect, artist, or inventor). This intelligence involves sensitivity to color, line, shape, space and the relationships that exist between these elements. It includes the capacity to visualize, to graphically represent visual or spatial ideas, and to orient oneself appropriately in a spatial matrix.

${ }^{16}$ Thomas Armstrong, Multiple Intelligences in the Classroom, (Alexandria, VA: Association for Supervision and Curriculum Development, 1994), 2. 
Bodily-Kinesthetic Intelligence: Expertise in using one's whole body to express ideas and feelings (e.g., as an actor, a mime, an athlete, or a dancer) and facility in using one's hands to produce or transform things (e.g., as a craftsperson, sculptor, mechanic, or surgeon). This intelligence includes specific physical skills such as coordination, balance, dexterity, strength, flexibility, and speed, as well as proprioceptive, tactile, and haptic capacities

Musical Intelligence: The capacity to perceive (e.g., as a music aficionado), discriminate (e.g., as a music critic), transform (e.g., as a composer), and express (e.g., as a performer) musical forms. This intelligence includes sensitivity to the rhythm, pitch or melody, and timbre or tone color of a musical piece. One can have a figural or "top-down" understanding of music (global, intuitive), a formal or "bottomup" understanding (analytic, technical), or both.

Interpersonal Intelligence: The ability to perceive and make distinctions in the moods, intentions, motivations, and feelings of other people. This can include sensitivity to facial expressions, voice, and gestures; the capacity for discriminating among many different kinds of interpersonal cues; and the ability to respond effectively to those cues in some pragmatic way (e.g., to influence a group of people to follow a certain line of action).

Intrapersonal Intelligence: Self-knowledge and the ability to act adaptively on the basis of that knowledge. This intelligence includes having an accurate picture of oneself (one's strengths and limitations); awareness of inner moods, intentions, motivations, temperaments, and desires; and the capacity for self-discipline, selfunderstanding, and self-esteem. ${ }^{17}$

Gardner chose to use the word "intelligence" instead of such less controversial terms as aptitude, talent, or competency. In an interview with Helen Weinreich-Haste, he said

"I'm deliberately being somewhat provocative. If I'd said that there are seven kinds of competencies, people would yawn and say 'yeah, yeah.' But by calling them 'intelligences,' I'm saying that we've tended to put on a pedestal one variety called intelligence, and there's actually a plurality of them, and some are things we've never thought about as being 'intelligence' at all."

${ }^{17}$ Ibid., 2, 3.

${ }^{18}$ Helen Weinreich-Haste, "The Varieties of Intelligence: An Interview with Howard Gardner," New Ideas in Psychology 3, no. 4 (1983): 47-65. ," New Ideas in Psychology 3, no. 4 (1983): 47-65. 
Going against the standard perception of intelligence as proposed by Alfred Binet (creator of the I.Q. theory) and accepted by the psychological and educational communities at large, Howard Gardner needed testing and proof to satisfy the skeptics. He set up his own tests for each of the seven intelligences and the criteria that each had to meet in order to be classified as a distinct intelligence and not simply an aptitude or talent. Here are three of the eight factors/tests that he used:

Potential Isolation by Brain Damage. Through his work at the Boston Veterans Administration, Gardner worked with individuals who had suffered accidents or illnesses that affected specific areas of the brain. In several cases, brain lesions seemed to have selectively impaired one intelligence while leaving all the other intelligences intact. A person with a lesion in the Broca's area (left front lobe) could have a significant portion of his linguistic intelligence damaged and thus experience great difficulty speaking, reading, and writing. Yet, he might still be able to sing, do math, dance, reflect on feelings, and relate to others. A person with a lesion in the temporal lobe of the right hemisphere might have musical capacities selectively impaired. Frontal lobe lesions could affect the inter- and intrapersonal intelligences (the frontal lobes store short- and long-term memory over the course of a person's life). ${ }^{19}$

The Existence of Savants, Prodigies, and Other Exceptional Individuals. Gardner suggests that in some individuals one can see single intelligences operating at high levels,

${ }^{19}$ Howard Gardner, Frames of Mind: The Theory of Multiple Intelligences (New York: Basic Books, 1983), 63. 
much like huge mountains rising up against a flat horizon. Savants are individuals who demonstrate superior abilities in one intelligence while the other intelligences function at a low level. There are examples of these individuals for all of the seven intelligences. In the movie Rain Man, Dustin Hoffman plays the role of Raymond, a logical-mathematical savant. Raymond can calculate vast numbers in his head, count toothpicks falling from a container, and does other incredible mathematical feats, yet he can barely function in society without the help of his brother. There are also savants who draw well (spatial intelligence), savants with amazing musical memories (can play a composition on one hearing), and savants who read complex material yet do not comprehend what they are reading (hyperlexics). ${ }^{20}$

Psychometric Findings. The final factor exists within the field of psychology in the area of psychometric findings. Standardized measures of human cognitive ability provide the "test" that most theories of intelligence and learning style use to ascertain the validity of a model. Although Gardner views himself as no champion of standardized tests, he suggests that we can look at many existing standardized tests for support of the theory of multiple intelligences. For example, the Wechsler Intelligence Scale for Children includes sub-tests that require linguistic intelligence (e.g., information, vocabulary), logical-mathematical intelligence (e.g., arithmetic), spatial intelligence (e.g., picture arrangement), and bodily-kinesthetic intelligence (e.g., object assembly). Other assessments survey personal intelligences (e.g., the Vineland Society Maturity Scale and 
the Coopersmith Self-Esteem Inventory). ${ }^{21}$ Thomas Armstrong provides a list of resources with which a student can be evaluated from school records or testing on an individual basis:

Linguistic: reading tests, language tests, the verbal sections of intelligence and achievement tests.

Logical-Mathematical: Piagetian assessments, math achievement tests, the reasoning sections of intelligence tests.

Spatial: visual memory and visual-motor tests, art aptitude tests, some performance items on intelligence tests.

Bodily-Kinesthetic: sensory-motor tests, some motor sub-tests in neuro-psychological batteries, the Presidential physical fitness test.

Interpersonal: social maturity scales, sociograms, interpersonal projective tests (e.g., Family Kinetic Drawing).

Intrapersonal: self-concept assessments, projective tests. ${ }^{22}$

There are several key points that Gardner wants teachers to remember when applying his theoretical model. First, MI theory proposes that each person has capacities in all seven intelligences. The seven intelligences function together in ways unique to each person. Some appear to possess high levels of functioning in most of the intelligences (Johann Wolfgang von Goethe, the German poet-statesman-scientistphilosopher), ${ }^{23}$ while others, such as those in institutions for the disabled, lack in all but the most basic aspects of the intelligences. Secondly, Gardner suggests that virtually everyone has the capacity to develop all seven intelligences to a reasonably high level

${ }^{21}$ Ibid., 66.

${ }^{22}$ Armstrong, 33.

${ }^{23}$ Howard Gardner, Multiple Intelligences: The Theory in Practice (New York: Basic Books, 1993), 50. 
of performance if given appropriate encouragement, enrichment, and instruction. In Chapter One of Frames of Mind, Gardner specifically mentions the Suzuki Talent Education program as an example of how individuals of modest musical talent have achieved a sophisticated level of proficiency in playing the violin or piano through a combination of environmental influences (parent involvement, exposure to classical music from infancy, and early instruction). The third point is that intelligences are always interacting with each other. In order to cook a meal, one must read the recipe (linguistic), possibly adjust the recipe for the size of group to be fed (logicalmathematical), develop a menu that pleases family members (interpersonal), and satisfy one's own appetite, as well (intrapersonal). Finally, there are many ways to be intelligent within each of the seven categories. A person may not be able to read well (dyslexic) yet may possess high linguistic abilities because he can tell an interesting story or has a large vocabulary. Also, a person may be awkward on the baseball field but possess superior bodily-kinesthetic intelligence in weaving or knitting intricate patterns in fabric. ${ }^{24}$

In summary, most classroom teachers have encountered the age-old problem of memory retention. MI theory provides a helpful perspective on this educational challenge. Memory, according to Howard Gardner, is intelligence-specific. There is no such thing as a "good memory" or a "bad memory" unless and until an intelligence is specified. Thus, one may have a good memory for faces (spatial/interpersonal intelligence) but a poor memory for names and dates (linguistic/logical-mathematical intelligence). This new perspective on memory suggests that students with "poor

${ }^{24}$ Ibid., 205. 
memories" may have poor memories in only one or two of the intelligences. Thomas

Armstrong suggests:

The problem, however, may be that their poor memories are in one or both of the intelligence areas most frequently emphasized in school: linguistic and logicalmathematical intelligence. The solution, then, lies in helping these students gain access to their "good" memories in other intelligences (e.g., musical, spatial, and bodily-kinesthetic). Memory training, or work involving memorization of material in any subject, should therefore be taught in such a way that all seven "memories" are activated. $^{25}$

${ }^{25}$ Armstrong, 147. 


\section{CHAPTER 3}

\section{MULTIPLE INTELLIGENCE THEORY AND MODERN VOCAL PEDAGOGY}

Can the principles of MI be integrated in the current teaching practices of voice instructors? In the opinion of this writer, MI can and should be used to enhance the effectiveness of voice instruction. The evidence previously reviewed in the writings of Howard Gardner is not limited to classroom instruction or elementary-level teaching. Human cognitive thought processes develop at different rates within each of the seven intelligences, and the principles are applicable to undergraduate and graduate vocal instruction. Are the principles already in use? To answer this question, one must examine the current practices of instruction within the field of vocal pedagogy. If voice instructors are varying their mode of instruction by exposing their students to various writers in voice literature (linguistic), explaining vocal physiology from a critical thinking paradigm (logical-mathematical), showing videos of vocal artists (spatial), demonstrating and leading exercises in breathing and relaxation (bodily-kinesthetic), playing audio examples of various song interpretations (musical), encouraging students to practice in groups and support/critique each other (interpersonal), and requiring students to keep journals to monitor their vocal progress (intrapersonal), then MI principles are already being utilized.

It is not my intent to say that these teaching ideas are something new. Most master teachers utilize variety in instruction to stimulate the imaginations of their students, to illustrate concepts that words cannot convey and external visual examination 
cannot see. In my experience, however, too few voice instructors vary their instruction by using all of these modalities. Instead, the predominant method of voice instruction takes place in a studio at the piano (musical) where a student reads the music (linguistic), communicates with the instructor (interpersonal), and is sometimes offered a few physical manipulations (kinesthetic).

\section{Drawbacks of Current Instruction Practices}

There are some drawbacks to this form of instruction. First, the success of the student often depends on the relational skills of the teacher. If the teacher's interpersonal skills are poor, the student might not tolerate this obstacle even though what he/she says might be true. If imagery is used on a student with strong logical/mathematical aptitudes without some scientific (logical) explanation, the student could become discouraged by the inability to understand what the teacher wants and to perform the desired vocal changes. Students with strong intrapersonal intelligence aptitudes care very little about interaction with an instructor and would definitely need other modalities to ensure their vocal success.

The second drawback lies in the personalization of instruction. Teachers who narrow the scope of their teaching by suggesting that their methodology is "THE WAY" are doing their students a disservice. No one voice teacher has all the answers because of our unique intellectual attributes, as described in MI. All experienced teachers have encountered students who are difficult to teach. The solution is in recognizing one's own weaknesses as an instructor and ameliorating those weaknesses with modalities that help to minimize their effect on students. What the concept of MI provides is a systematic 
description of research that shows why instructors of all types should vary their methods of instruction and how this can be accomplished in lesson plans and exercises. These principles can apply to practical vocal pedagogy and vocal pedagogy texts used in classroom instruction.

\section{Thomas Armstrong}

The writings of Thomas Armstrong are a valuable resource on the practical application of MI theory in the classroom. A protégé of Howard Gardner, he collaborated in MI research studies and has generated many helpful tables to guide instructors. His "Summary of the Seven Ways of Teaching" (see table 1$)^{26}$ provides the template on which my evaluation of the texts will be based. The table includes teaching activities, teaching materials, and instructional strategies that can be incorporated easily into all venues of voice instruction.

${ }^{26}$ Ibid., 56. 
TABLE 1.

Summary of the "Seven Ways of Teaching"

\begin{tabular}{|c|c|c|c|}
\hline Intelligence & $\begin{array}{l}\text { Teaching Activities } \\
\text { (examples) }\end{array}$ & $\begin{array}{l}\text { Teaching Materials } \\
\text { (examples) }\end{array}$ & $\begin{array}{l}\text { Instructional } \\
\text { Strategies }\end{array}$ \\
\hline Linguistic & $\begin{array}{l}\text { lectures, discussions, } \\
\text { word games, } \\
\text { storytelling, choral } \\
\text { reading, journal } \\
\text { writing, etc. }\end{array}$ & $\begin{array}{l}\text { books, tape recorders, } \\
\text { typewriters, stamp } \\
\text { sets, books on tape, } \\
\text { etc. }\end{array}$ & $\begin{array}{l}\text { read about it, write } \\
\text { about it, talk about it, } \\
\text { listen to it }\end{array}$ \\
\hline $\begin{array}{l}\text { Logical- } \\
\text { Mathematical }\end{array}$ & $\begin{array}{l}\text { brain teasers, problem } \\
\text { solving, science } \\
\text { experiments, mental } \\
\text { calculation, number } \\
\text { games, critical } \\
\text { thinking, etc. }\end{array}$ & $\begin{array}{l}\text { calculators, math } \\
\text { manipulatives, science } \\
\text { equipment, math } \\
\text { games, etc. }\end{array}$ & $\begin{array}{l}\text { quantify it, think } \\
\text { critically about it, } \\
\text { conceptualize it }\end{array}$ \\
\hline Spatial & $\begin{array}{l}\text { visual presentations, } \\
\text { art activities, } \\
\text { imagination games, } \\
\text { mind-mapping } \\
\text { metaphor, } \\
\text { visualization, etc. }\end{array}$ & $\begin{array}{l}\text { graphs, maps, video, } \\
\text { LEGO sets, art } \\
\text { materials, optical } \\
\text { illusions, cameras, } \\
\text { picture library, etc. }\end{array}$ & $\begin{array}{l}\text { see it, draw it, } \\
\text { visualize it, color it, } \\
\text { mind-map it }\end{array}$ \\
\hline Bodily-Kinesthetic & $\begin{array}{l}\text { hands-on learning, } \\
\text { drama, dance, sports } \\
\text { that teach, tactile } \\
\text { activities, relaxation } \\
\text { exercises, etc. }\end{array}$ & $\begin{array}{l}\text { building tools, clay, } \\
\text { sports equipment, } \\
\text { manipulatives, tactile } \\
\text { learning resources, etc. }\end{array}$ & $\begin{array}{l}\text { build it, act it out, } \\
\text { touch it, get a "gut } \\
\text { feeling" of it, dance it }\end{array}$ \\
\hline Musical & $\begin{array}{l}\text { superlearning, rapping, } \\
\text { songs that teach }\end{array}$ & $\begin{array}{l}\text { tape recorder, tape } \\
\text { collection, musical } \\
\text { instruments }\end{array}$ & $\begin{array}{l}\text { sing it, rap it, listen to } \\
\text { it }\end{array}$ \\
\hline Interpersonal & $\begin{array}{l}\text { cooperative learning, } \\
\text { peer tutoring, } \\
\text { community } \\
\text { involvement, social } \\
\text { gatherings, } \\
\text { simulations, etc. }\end{array}$ & $\begin{array}{l}\text { board games, party } \\
\text { supplies, props for role } \\
\text { plays, etc. }\end{array}$ & $\begin{array}{l}\text { teach it, collaborate on } \\
\text { it, interact with respect } \\
\text { to it }\end{array}$ \\
\hline Intrapersonal & $\begin{array}{l}\text { individualized } \\
\text { instruction, } \\
\text { independent study, } \\
\text { options in course of } \\
\text { study, self-esteem } \\
\text { building, etc. }\end{array}$ & $\begin{array}{l}\text { self-checking } \\
\text { materials, journals, } \\
\text { materials for projects, } \\
\text { etc. }\end{array}$ & $\begin{array}{l}\text { connect it to your } \\
\text { personal life, make } \\
\text { choices with regard to } \\
\text { it }\end{array}$ \\
\hline
\end{tabular}




\section{CHAPTER 4}

\section{ANALYSIS OF VAN CHRISTY AND JAN SCHMIDT TEXTS}

The Van Christy and Jan Schmidt texts are widely used in class voice courses at colleges and universities across the United States. In the remaining sections of this paper, I will analyze each text according to the MI parameters and provide suggestions on the integration of MI with these texts and in daily lesson plans. To provide the largest scope for the application of MI, the chapter from each text on song preparation has been chosen. Within these chapters, aspects of lesson order, variety of exercises, and the overall outline will be explored to determine to what extent each author is reaching the education ideals of the seven intelligences.

In Foundations of Singing, Christy begins the chapter on song preparation with a question that stimulates thought from an intrapersonal perspective, "What is the best way to learn the words and music of songs so that I can sing them expressively and confidently?" 27 The value of this approach is in encouraging the students to take ownership of a composition even though he/she may have had no part in its creation or in the society that it describes. He further explores the nature of his first question with guidelines that require introspection:

1. Choose words that you can believe in. If words don't make sense to you, they are harder to learn, and it is harder to motivate yourself to sing expressively.

2. Choose an easy song and do it well, rather than a hard song that you can't finish. If all your energy goes into learning difficult rhythms or rapid-fire words, you can't give much thought to improving tone quality.

${ }^{27}$ Christy, 35. 
3. Choose a short song over a longer one. At first, you will learn more by doing several short songs than by sticking to one long one. Also, your teacher can give you more help in lessons if you sing a short song several times rather than a long
song once (emphases mine). ${ }^{28}$

Christy concludes this section of the chapter with a line of reasoning that succinctly answers his guiding question: "Identify something you really like in your song." This phrase and others, such as "make a mental note if it," "remember why you liked it," and "does it appeal to you because of the mood, a mental picture, or an idea?" are characteristic of intrapersonal instructional strategies (see table 1). This tendency to focus on the use of imagery and intrapersonal reflection is not an isolated instance within this text. It would appear that this modality is inherent to Christy's writing style, as evidenced in his previously quoted material on "resonance."

In contrast, Schmidt's writing style and instructional objectives contain very few intrapersonal strategies in the chapter on "Learning a Song." The only example of significance occurs near the end of the chapter:

When a song has been thoroughly worked through, first musically, then technically, it is time to consider how to communicate it. Videotape is a great help when working to improve this area. Practicing before a full-length mirror is a useful alternative. The singer needs, quite literally, to picture the things being sung about. Concentration, which must also be practiced, is the key.

If a performer identifies strongly enough with the text of a song, actually picturing himself in a place, a situation, or as a certain person, that is all he will be able to think about. The term "acting" is often misinterpreted. "Being," not "acting," is what touches audiences (emphases mine). ${ }^{29}$

${ }^{28}$ Christy, 35 .

${ }^{29}$ Schmidt, 25. 
Is it important to have an intrapersonal component in a lesson on song learning? Yes, for the following reasons. First, it is vital for all students to be able to connect with the overall mood(s) of any song. Appropriate expression (mood) is best gained through careful research into a song's historical and sociological contexts. Once a clear understanding of these contexts is reached, the student is able to determine the mood(s) of the character(s) and apply appropriate expressive devices. At times, a clear realization of the mood(s) will bring unconscious musical reaction from the student that no amount of external coaching will realize. Such is the psychological interaction of emotions and music to create true art.

Secondly, intrapersonal learning strategies are important for keeping track of vocal progress on a daily, monthly, and yearly basis. This can be accomplished by encouraging each student to keep a diary in which he/she records types of exercises used in warm-up, progress on individual songs, and overall impressions or improvements. These diaries are a helpful tool for the student in determining the balance of vocal study, where and when breakdowns have occurred, and the overall direction and improvement made. They are an important diagnostic tool for the teacher as well.

Schmidt's lack of an intrapersonal component limits the student's emotional "buy in" during song learning. Research on long-term memory, conducted by Benjamin Bloom in the late 1950s, proves the importance of an intrapersonal component in song learning. He concluded that when information has meaning/relevance for the student, memory is retained in larger amounts and for a greater length of time. From this research, he developed a graduated system of learning levels still highly regarded and 
widely used by educators today. The cognitive hierarchy of Bloom's taxonomy illustrates the need of synthesis for long-term memory to be most effective:

Knowledge: Rote memory skills (text and music memorization).

Comprehension: The ability to translate, paraphrase, interpret, or extrapolate material (determining the mood and meaning of the text by paraphrase).

Application: The capacity to transfer knowledge from one setting to another (application of performance directions on the printed page for all songs).

Analysis: Discovering and differentiating the component parts of the larger whole (analysis of the physiology of voice production).

Synthesis: Weaving together component parts into a coherent whole (the performance).

Evaluation: Judging the value or utility of information using a set of standards (student evaluations of performances in classroom, master class, and recital situations). ${ }^{30}$

In the synthesis phase, the student realizes how the information applies in a variety of situations and uses them in a cohesive package called "the performance." When applied to song learning, he/she will begin to form an opinion about the mood of a song when the text is first read and as the research on the history and sociology of the song is conducted. Bloom's taxonomy provides a kind of quality control mechanism with which an instructor can judge, through verbal inquiry and written testing, how deeply students' minds have been stirred by a multiple intelligence curriculum.

Though "Define the historical period, mood, and type of song" is listed as number two on Schmidt's list of song learning steps, she does very little to elaborate on what she means in the body of her discussion:

${ }^{30}$ Benjamin Bloom, Taxonomy of Educational Objectives (New York: David McKay, 1956), 12. 
Check the dates of the composer to find out if the song is fairly recent or from some other period. By considering the text and music, determine the overall style of the song. Was it intended to be a folk song, a song for worship, for the theater, or for some other use entirely?

"Beneath a Weeping Willow's Shade" was written during the lifetime of George Washington; therefore, the picture of men and women in the dress of that time dancing to the music of the harpsichord might readily be imagined. The feeling is light and buoyant, with an accent on every third beat. ${ }^{31}$

Checking this selection against the teaching activities and instructional strategies for intrapersonal intelligence listed by Thomas Armstrong (table 1), one sees no suggestion of independent study, course of study, personal life connection, or mention of mood that might be internalized by the student. This contrasts with Christy's emphasis on an intrapersonal style of instruction.

Interestingly, Schmidt and Christy separate learning a song from performance practice. Both writers choose to deal with performance practice, physical expression, and concepts of musical theatrics in later chapters as a progression from simple vocal foundations to more complex performance practice issues. Though it might seem like the student has enough to think about, it is the opinion of this writer that concepts of facial expression, body movement, and stage deportment are often introduced too late. To expect that a student will make an easy transition to animated, expressive performance after the technical aspects of a song have been practiced dozens of times without it is unrealistic. It is important for teachers to encourage students to practice in front of a mirror, to view their facial expression and body movement as an audience would, and to suggest appropriate changes of focus and facial expression closely allied with the text

${ }^{31}$ Schmidt, 20. 
early in the song learning process. Such a process will produce a more polished product as the student associates body movement, text meaning, and musical change as an integral whole. Intrapersonal teaching strategies can form a solid foundation on which to build "song learning" principles.

The second contrasting feature of the Christy and Schmidt texts is in the area of logical-mathematical instructional strategies. These strategies include brain teasers, problem solving, mental calculation, and critical thinking components from a voice instruction paradigm. Direct application in a lesson plan would include asking the students to quantify, think critically, and conceptualize vocal concepts. An obvious area in which to integrate this methodology within song learning is rhythm and meter. Christy provides an elaborate explanation of rhythm, meter, and text matching from a logicalmathematical perspective.

Notice that "When Laura Smiles" is written in triple meter, which means an overall rhythmic pattern of three beats per measure. Sit down at a table with the song in front of you. Tap the meter on the table top with one hand or both. Tap the three beats this way: beat 1 near the book, another beat a few inches away, and a third beat further away ... Don't tap all the beats in one spot, because you may lose track of which beat is which. Now speak the poem aloud rhythmically while your hands tap the meter.

In the first measure there is one syllable to each tap of your hand, but in the second, the word "smiles" lasts through three taps...

$\begin{array}{llllll}\text { tap } & \text { tap } & \text { tap } & \text { tap } & \text { tap } & \text { tap } \\ 1 & 2 & 3 & 1 & 2 & 3 \\ \text { when } & \text { Lau- } & \text { ra } & \text { smiles, --.-- } & \text { - }\end{array}$

You might feel a little conflict already between the rhythm of the music and the words. When you first read the poem, its rhythm went this way: 


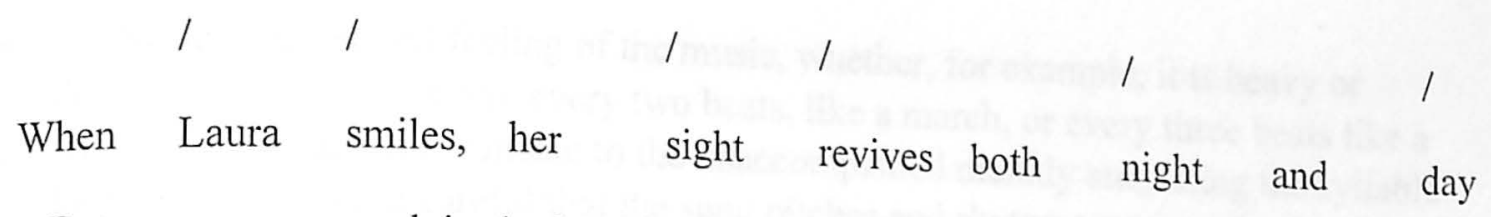

But now as you speak in rhythm, the strong syllables are sometimes on beat 1 and sometimes on beat 2 . Elizabethan musicians liked rhythmic shifts like this and used
them to keep their music lively. ${ }^{32}$

One advantage of Christy's approach is the coupling of logical-mathematical critical thinking components and bodily-kinesthetic guided practice (touch it). Individuals lost in the abstract explanation of strong and weak beats could be drawn in by the clear directions of how to practice the rhythmic pulse. Though there is no overt reference to utilizing MI within this text, this is one technique of problem solving suggested by Howard Gardner and Thomas Armstrong. When a concept is difficult for students to grasp, the coupling of instruction strategies can be a valuable tool:

To illustrate what forms of problem solving "look" like, it may be helpful to review the thinking processes of eminent individuals whose discoveries have helped shape the world we live in. By studying the "end states" of specific problem-solving processes in these great people, educators can learn much that can help foster the same sort of processes in their students.

Many thinkers have used imagery and picture language (spatial intelligence) to help them in their work. A study of Charles Darwin's notebooks reveals that he used the image of a tree to help him generate the theory of evolution: "Organized beings represent a tree, irregularly branched, ... as many of terminal buds dying as new ones generated." ${ }^{33}$

There is no logical-mathematical instructional component in Schmidt's chapter on learning a song. In fact, there is no clear explanation of meter, rhythm, and their relationship to the text anywhere in this section. The closest reference appears when she says:

${ }^{32}$ Christy, 38 .

${ }^{33}$ Howard Gardner, Creating Minds (New York: Basic Books, 1993), 48. 
Notice the general feeling of the music, whether, for example, it is heavy or descriptive (with an accent every two beats, like a march, or every three beats like a waltz .... Return in the music to the unaccompanied melody and, using the syllable la, sing along, being careful that the sung pitches and rhythms are exactly the same as those heard on the piano. This step should be repeated as many times as necessary to accomplish this goal ... In "Beneath a Weeping Willow's Shade," measures 8, 9, and 35 might be confusing because of the dotted rhythms (notes with dots following are held half again longer than they would be normally, resulting in the shortening of the note that follows). ${ }^{34}$

It is apparent in this explanation that the author assumes more than a basic knowledge of concepts of meter and rhythm for two reasons. First, Schmidt assumes that the student knows the difference between simple and compound time without a clear explanation (even in her chapter on "Music Reading" found later in the book). Secondly, Schmidt chooses "Beneath a Weeping Willow's Shade" as a first song with its compound meter (6/8 time). If the text is designed for intermediate or advanced students, such brevity might be appropriate. As a "basic" text, some elaboration as contained in the Christy text is necessary in order to reach students' logical-mathematical and bodily-kinesthetic aptitudes at the beginning level.

Schmidt chooses, instead, to rely purely on the student's musical intelligence through the use of her accompaniment tape and compact disc. At face value, using musical instructional strategies would make the most sense when learning a song. Recording one's practice is an excellent way to keep track of progress. It is also helpful at some time during a student's song learning process to listen to another artist's interpretation. When care is taken to choose a tasteful rendition, many ideas of dynamics, phrasing, and text nuance can be gained that may not be indicated in the score. Schmidt's

${ }^{34}$ Schmidt, 20, 21. 
accompaniment recordings do not offer these insights (ideas) because they lack vocal performance examples. They are piano renditions with reinforced melody. This writer's argument is not with the modality (musical intelligence) but in the way and frequency of its use. In the ten steps of Schmidt's "Sample Song-Learning Method," five of them contain some reference to listening to a recording:

Record melody, first with, then without, accompaniment. Develop familiarity with both versions.

Define the historical period, mood, and type of song.

Sing along with unaccompanied melody using the syllable la, marking difficult places with an $x$. Practice until rhythm and pitches are secure.

Whisper the words of the text in rhythm while listening to the unaccompanied melody.

Sing text and pitches with unaccompanied melody until learned securely. Sing with accompanied melody.

Read the text aloud and analyze its meaning.

With commas, mark appropriate breaths. Circle expression markings.

Concentrate on the use of good vocal technique in the song.

Using a tape recorder, review articulation.

Practice "selling" the song by picturing its text and performing it with great and consistent energy (emphases mine). ${ }^{35}$

The frequency of musical instructional strategies as listed in these ten steps and elaborated in the body of this chapter makes it the most definitive characteristic of her approach. The lesson plan revolves around having the student listen to the audio

${ }^{35}$ Ibid., 26. 
recordings of accompaniment Schmidt provides as a companion to the text and parroting the melodic intervals and piano interpretation until note accuracy is reached.

There are some inherent flaws to this method. The first is where learning from a recording lies on the Bloom's Taxonomy scale. Memorization of facts (rote memory) is listed on level 1, the most basic level where information is internalized with little thought of application or analysis at future times. Students who are encouraged to learn music in this way will sidestep sightsinging and ear training concepts. When confronted with difficult melodic intervals, they will opt to listen to the tape rather than attempting these on their own. Rote learning in music does nothing to empower the student to read the music using intellect and will. Without a recording, the accompaniment-dependent student might avoid ever learning to read music. Household pets function at this level with positive and negative reinforcement, but students should be encouraged to go well beyond this domain where concepts learned in primary songs can be reused in more advanced selections (application, analysis, and synthesis of Bloom's taxonomy).

Reliance only on musical instructional strategies could isolate students who are low in musical intelligence aptitude or are just being introduced to the world of vocal music. Those who are bored with only a "listen and do" approach can often be reached by "tapping in" to their other intelligence strengths. The titles of the texts Foundations in Singing and Basics of Singing predetermine their use as beginning voice texts.

Beginning class voice enrollment in community and undergraduate colleges seek to meet the needs of a student population with many different aims and goals. It is very likely that students of all vocations will attend these classes for reasons of self-fulfillment (intrapersonal), not because they have significant musical experience or aptitude. 
In the area of spatial instructional strategies, Schmidt includes some helpful ideas:

When a song has been thoroughly worked through, first musically, then technically, it is time to consider how to communicate it. Videotape is a great help when working to improve this area. Practicing before a full-length mirror is a useful alternative. The singer needs, quite literally, to picture the things being sung about. ${ }^{36}$

How these ideas are to be incorporated to utilize fully their potential needs some

elaboration. The use of videotape during performance sessions is a two-fold way of helping the student. First, it helps spatially-oriented students visualize elements of facial expression, body positioning, and movement associated with stage performance. Nuance of eye focus, head positioning, and eye expression can be played and replayed in seconds where explanation in lecture could take hours. Secondly, it is useful in a class or group situation. Whenever possible, master classes and student performances should be videotaped for later viewing. Students should be encouraged to notice (take notes on) characteristics of their performances and the performances of others. With care and consideration the instructor can help these visual evaluations to be a positive influence in the student's visual vocal growth.

It is unfortunate that the Christy text lacks any spatial instructional strategies. Their inclusion would augment an already balanced presentation of teaching through other intelligences in his song learning chapter.

Linguistic instructional strategies are evident in both texts through extensive verbal explanations of vocal concepts, but nowhere in either text are students overtly encouraged to do independent research or invited to discuss vocal concepts using a list of guiding questions at the end of the chapter. Instructors often overlook developing this

${ }^{36}$ Armstrong, 25. 
intelligence area because of its assumed coverage in the forms of lecture and class

readings. The importance of research will be elaborated in the application of MI teaching strategies found in Chapter 5 following.

The only facet not included in either text is in the area of interpersonal

intelligences. Teaching in this area could easily be incorporated in the theatrics of singing through the use of mime, role play, and group feedback on the visual aspects of performance practice. As previously mentioned, theatrics in singing could and should be incorporated at the onset of the song learning process. The artistic demands of musical theater, opera, and even expressive recital singing require a thorough understanding of acting and stage movement. Daniel Helfgot emphasizes the need in The Third Line, a book dedicated to the premise that singers need to have much more than beautiful voices:

In 1984 the National Association of Schools of Music published a survey of university- or conservatory-based opera training programs entitled "The Education and Training of the Singer-Actor." This survey revealed the deep bias toward exclusive training of vocal skills in the development of opera performers. Although virtually every program claimed to require training in languages, acting, dance, martial arts, and other skills, students were rarely required to demonstrate actual competence in these areas before receiving their degrees. Too often, students were thrust into full student productions of operas with no stage background except voice instruction. They were expected to learn stage movement and acting on the fly. ${ }^{37}$

As old as this study is, the lack of emphasis in the Christy and Schmidt texts shows that little has changed, at least in these contemporary vocal pedagogy texts. The sophistication of modern audiences, sparked by the boom in video technology, has little tolerance for the sloppy and unexpressive visual effects brought by the studio-trained singer. Voice instructors of the future will need to incorporate visual aspects of acting

${ }^{37}$ Daniel Helfgot, The Third Line (New York: Schirmer Books, 1993), 5. 
and stage movement at the foundation of vocal training if the vocal arts of musical theater, opera, and recital are to thrive or survive. 


\section{CHAPTER 5}

\section{APPLICATION}

From the preceding analytical study, I conclude that neither Christy nor Schmidt wrote their vocal pedagogy texts from an MI paradigm. The writer's purpose is not to debate which is a better text but to suggest ways that principles and practical applications of MI theory can be used with any vocal pedagogy text. In Open Ear, a publication dedicated to sound and music in health and education, Wendy Zieve describes the value of using music in the classroom to enhance intellectual development. She suggests that active music listening and research have a positive emotional effect on students' study habits beginning at the preschool level and continuing through the high school years. ${ }^{38}$ Her assertions could apply to the area of vocal pedagogy, as well. Applying the MI principles as presented in the writings of Howard Gardner and Thomas Armstrong, the following order is suggested when preparing/learning a song. For demonstration purposes, I have chosen the song "Liebst du um Schönheit" by Clara Schumann, found in the Schmidt text on page 251 .

\section{Research}

Research should be the first step. Though a helpful sketch is included in the text on page 71 , students should be encouraged to search the library for details of Clara Schumann's life, the sociology of the time period, and historical items that would have

${ }^{38}$ Wendy Zieve, "Multiple Intelligences Focus on Music," Open Ear (Summer 1994): 20-22. 
affected her as a composer. Research would include reading from at least three different sources and compiling the information in a report of appropriate size (depending on the composer). These reports can be shared with other class members using oral presentation. Instructional strategies within this step are linguistic and interpersonal in nature, but other teaching tools could be used to reach other intelligence strengths. A logical-mathematical component (critical thinking) could be incorporated by having the students provide copies of their report for each class member to read and evaluate. Initially, students might think this step is a bit harsh, but by providing positive criteria with which to judge each report, the instructor could prepare the students for the later educational steps of program notes, thesis, and dissertation where a committee of several members evaluates written material.

Students strong in spatial intelligence could be reached using educational video on the lives of the composers. Taped PBS specials (within copyright guidelines) and larger video companies/stores like Opera World or Tower Records can provide a variety of choices for the discriminating instructor. The impact of video is increased when students are encouraged to fill in an outline or take notes during the video performance (coupling of spatial and linguistic strategies). An interpersonal component of group discussion following the video is a fine way to summarize and encourage students to share their perceptions of video content. It is often during this sharing time that an instructor finds out whether or not the video was effective in portraying the composer. 
Text

At some time during the research phase, the student will discover the source of the song text. Text study is vital when determining the mood to be expressed in the song, particularly when the text is in a foreign language. Even if a translation is provided, students should be encouraged to use a foreign language dictionary to check the translation for accuracy (linguistic strategy). If the English translation is rhyming, this could be an indication of paraphrase and alteration provided by the editor. By translating word for word, the true meaning of the text can be discovered, particularly when coupled with the origin and time period when it was written. In the study of "Liebst du um Schönheit," the student would discover that the translation was provided by a native German, Metche Franke, and that the translation is not rhyming. Translation should still be encouraged, however, to discover why the sentence markings are different in the German and English text and to make sure of textual accuracy. Another benefit of student translation is the possibility that this exercise will awaken a student's interest in studying other languages.

Language study is vital for fluency in singing and communication. Daniel Helfgot asserts:

The moment singers emit sounds rather than meanings, they are not performing ... they are doing something else - something parrots can do. Even if merely emitting sounds works for a time, when singers fail to express meanings, they are cheating their audiences. They are also cheating themselves of most of the pleasure of performing, and shortchanging the librettist and the composer. ${ }^{39}$ 
For this reason, it is important for a singer to study every foreign language he/she sings to ensure accuracy in communication. Voice instructors should encourage the beginning of language study at the onset of vocal study through active explanation and demonstration of language phonetics.

In studying the Schumann song, bodily-kinesthetic instructional strategies would be effective in transmitting principles of German language phonetics, beginning with an explanation of what "umlauten" are: "The 'o' vowel in the word 'schönheit' has two dots above it called 'umlauten.' The vowel sound is made by making the lips into an ' 0 ' shape and holding the tongue in the 'ee' position." Following the explanation, the instructor would lead the class (student) in a call-response recitation of the text, word by word, then phrase by phrase. The instructor listens for mispronunciations and, by describing/demonstrating tongue and lip position for each sound, has each student demonstrate the correct sound. This bodily-kinesthetic strategy of vocal guided practice should be reinforced periodically during the song process using speaking and singing as a medium.

Musical instructional strategies can be used to contrast the differences and to demonstrate language nuances that are difficult to explain. Students should be encouraged to listen to native singers and foreign language tapes, particularly if they include dialogue by several individuals. Through careful study, small details of sentence structure, metrical accent, and use of the pause are subliminally recorded by the mind and can influence non-native language patterns almost immediately.

Musical aptitudes not only tune themselves to musical sounds but to language sounds, as well, noting the inflections of dialects and nuances of vowel sounds. These 
techniques apply as well to musical recordings in foreign languages. Whenever possible, a recording of a song by an artist native to that language should be used for student study. Using examples of spoken and sung language, students can get a clear idea of the entire spectrum of sound. For "Liebst du um Schönheit," it would be ideal to have a recording sung by a German, female artist available for student listening. Finally, the accessibility of foreign television networks on cable provides opportunity for spatial instructional strategies to be used. Videotape gives visual references with language for easier understanding of context.

\section{Mood}

When text study is complete, a singer should have a firm grasp of the mood (moods) of the song. The mood is the summary of emotions within a song. Is it joyful, sad, angry, playful, reflective, passionate, exuberant, or any number of other emotion adjectives? In order to pinpoint accurate descriptives, it may be necessary to summarize the text in a few sentences. Intrapersonal and interpersonal instruction strategies could be applied at this step. As the students develop their summaries, they might reflect on how the emotions portrayed in the text apply to experiences in their own lives. These experiences could be shared in group discussion (interpersonal) or privately in essay form. Once the moods have been identified, appropriate facial expressions should be applied to each using a combination of mirror feedback, paired learning, and group critique. In mirror feedback (intrapersonal), the student explores a variety of facial expressions in front of a mirror, carefully noticing which muscles respond in varying motions. In "Liebst du um Schönheit," the mood being expressed is joy, the joy of the 
many facets of love. It is important that the instructor emphasize the role of the eyes in facial expression:

Eye focus is such a key concept for the stage that it requires a good deal of attention from all performers. There are introverted focuses, extroverted focuses, wandering focuses, lack of focus, but, just as there is no such thing as "nonaction" on the stage, nothing can happen onstage without focus. The focus is the thought, as well as its direction or its source. The thought is visible through the performer's eyes. Without the eyes focusing, even if the performer tries to show a lack of specific focus, there is no thought. Without the thought, there is no story to deliver - there is no purpose of expression. ${ }^{40}$

Where a singer may be limited by aspects of vocal production in the amount of mouth expression to use, the eyes are always free to communicate. They may be widened, narrowed, framed by a smile or frown, shifted, or focused on one point in an intense way. Factors of eye placement, nose prominence, eyebrow length and height, and facial shape, affect how we are perceived by others. Individuals, by their facial structure, are seen as severe, pleasant, expressionless, or mean. Using a mirror, all of these manipulations must thoroughly be explored by the student, noticing the limitations of personal facial structure.

In paired learning (interpersonal), students face each other and explore varieties of emotions through facial expression, providing feedback to each other when expressions are not appropriate. The emotion adjectives can be called out by the instructor, or by either one of the paired students as they alternate during the exercise. Group critique (interpersonal) is a valuable technique to use during song performances in a master class format. After each student has completed his/her performance, the instructor moderates a group discussion/evaluation purely from a visual paradigm. This 
tool can be a refreshing break from a purely musical focus to which students and instructors are prone when preparing for voice juries or recitals. When aspects of mood as evidenced in facial expression are firmly established, theatrics are easily incorporated in the forms of body position, movement, and gesturing later in the song learning process.

\section{Meter}

How often the phrase "Singers can't count" is uttered in musical circles. A clear understanding of the metric pulse is vital to later rhythmic complexities in music. Unfortunately, metrical concepts are often taken for granted in higher education. To expect that all students have basic musical fundamentals is no longer realistic, given the state of affairs in the musical arts in America today. The movie, Mr. Holland's Opus, publicly revealed the lack of interest and funds for music in public education on the elementary and high school levels.

A clear explanation of meter concepts should be included in all vocal pedagogy texts. "Liebst du um Schönheit" is in common time, a good starting point when elaborating on note values (e.g., a quarter note being a quarter of a measure in common time). Once the measure has been subdivided (logical-mathematical strategies) into two half-notes, four quarter-notes, eight eighth-notes, and sixteen sixteenth-notes (to equal one measure), the concept of strong and weak beats can be illustrated using clapping (bodily-kinesthetic). Students clap with even weight on all beats in common time. The instructor asks, "How do you know what meter is being clapped when all claps sound the same?" This should be a springboard for a lively discussion that can branch out into an explanation of the differences between duple and triple meters and which beats are 
accented and unaccented. The analogy of the heartbeat, its constant pulse and weak and strong beats, could be a meaningful illustration. Part of the meter/rhythmic complexity in "Liebst du um Schönheit" is the tendency of the melodic rhythm to rest on a strong beat (beat 1). A bodily-kinesthetic technique used by Christy in his song learning chapter could be utilized here, as well. The instructor could have the students tap or pat their desks with their hands on beat 1 to keep from singing on it. The regular occurrence of the rest on beat 1 and on the "and of 1 " would make this device a helpful one at the beginning of song learning. Gradually, the instructor needs to insist that the students keep an internal pulse in the mind rather than with the hand, foot, or other part of body to minimize unconscious body movements that will distract the audience.

Once principles of meter have been introduced and reinforced through guided practice (clapping), their application to the text should be emphasized. As an exercise, an instructor could take several poetry examples, distribute copies to the class, and ask what musical meters would fit each text (logical-mathematical strategy through critical thinking). A class member might come up with several meters for a given text. This would be a great point to launch into a discussion of how composers choose text and often prefer one author over another. The main point an instructor should emphasize is that song meter and text in great music are linked in a bond not unlike chemical compound. When they are joined, they elevate each other far above and different from what they were separately. 


\section{CHAPTER 6}

\section{CONCLUSION}

From an MI perspective, neither the mechanistic nor the aural imagery "schools" are in themselves complete methods for contemporary voice instruction. For students high in bodily-kinesthetic and logical-mathematical aptitude, mechanistic techniques of external manipulation, detailed physiological explanation, and cause-and-effect experimentation could be effective. Imagery techniques of introspection, mind pictures, and metaphor could be used to explain voice concepts to students of high intrapersonal, spatial, and linguistic aptitudes.

Together, techniques from both methods can cover the majority of intelligences. With creative integration of interpersonal group and interactive musical teaching strategies, the ideal of teaching to all seven intelligence areas can be reached.

In many ways, the bond of MI theory and vocal pedagogy has the potential to elevate voice instruction far above what it has been. First, the MI principles can be applied in the additional facets of song learning not already mentioned in previous chapters: breathing/phrasing, song form, dynamics and shadings, and memorization, with equal effectiveness. MI teaching strategies can be adapted to fit voice literature, diction, and opera workshops, whatever the instructor's teaching style may be. The only limitation is the instructor's desire to find out what his/her intelligence strengths are and to purposefully seek to understand student capabilities as evidenced in testing results and classroom behavior. Helpful hints on the application of MI, the discovery of intelligence strengths, and tables of data further elaborating research in this area may be found in 
Multiple Intelligences in the Classroom by Thomas Armstrong (the source of table 1, above, page 20). If time is an inhibiting factor in the research/application of MI, a safe way to integrate these teaching principles is to:

1. Try to use teaching strategies from at least two intelligences for every concept taught (concepts of breathing could be taught from a bodilykinesthetic and interpersonal paradigm using a partner system).

2. Vary the use of intelligences for every class period (i.e., one class period the instructor uses a video [spatial] to show theatrics of singing principles; the next, students work with partners [interpersonal] to show emotion through pantomime).

3. When one teaching strategy doesn't work, try several others. It may be that an instructor's teaching style doesn't match with the teaching strategy. Persistence and variety will help an instructor reach a maximum number of students.

4. Every month (or semester) use all the MI teaching strategies for the seven intelligences. This will ensure that the material has been covered from every facet.

Careful thought and advanced planning will help instructors integrate Multiple

Intelligence Theory and vocal pedagogy. "Man, by nature, desires to know." ${ }^{\not 11}$ It is our privilege to share the "how" and "why" of the human voice. 


\section{SELECTED BIBLIOGRAPHY}

Armstrong, Thomas. Multiple Intelligences in the Classroom. Virginia: Association for Supervision and Curriculum Development, 1994.

Benton, William. The Works of Aristotle, vol. 2. Chicago: Encyclopedia Britannica, 1952.

Choksy, Lois. The Kodály Method. Englewood Cliffs, NJ: Prentice Hall, 1988.

Christy, Van. Foundations in Singing. $5^{\text {th }}$ ed. Dubuqe, IA: Wm. C. Brown, 1990.

Coffin, Berton. Historical Vocal Pedagogy Classics. London: Scarecrow Press, 1989.

Garcia, Manuel. A Complete Treatise on the Art of Singing: Part One . New York: Da Capo Press, 1984.

Gardner, Howard. Creating Minds. New York: Basic Books, 1993.

. Frames of Mind: The Theory of Multiple Intelligences. New York: Basic Books, 1983.

Multiple Intelligences: The Theory in Practice. New York: Basic Books, 1993.

Harpster, Richard. Technique in Singing. New York: Schirmer Books, 1984.

Helfgot, Daniel. The Third Line. New York: Schirmer Books, 1993.

Johnstone, Douglas. "The Teaching of De Reszke." Music and Letters 1 (July 1925): 112 .

Lawrence, David. The Voice Once Over Lightly. Philadelphia: Voice Foundation, 1988, transcript of video recording.

Schmidt, Jan. Basics of Singing, $4^{\text {th }}$ ed. New York: Simon and Schuster Macmillan, 1998.

Weinreich-Haste, Helen. "The Varieties of Intelligence: An Interview with Howard Gardner." New Ideas in Psychology 3, no. 4 (1983): 47-65.

Zieve, Wendy. "Multiple Intelligences Focus on Music." Open Ear (Summer 1994): 2022. 